AperTO - Archivio Istituzionale Open Access dell'Università di Torino

The Italian middle school in a deregulation era: modernity through path-dependency and global models

This is a pre print version of the following article:

Original Citation:

Availability:

This version is available http://hdl.handle.net/2318/1523594

since 2015-12-16T11:22:54Z

Published version:

DOI:10.1080/03050068.2015.1033249

Terms of use:

Open Access

Anyone can freely access the full text of works made available as "Open Access". Works made available under a Creative Commons license can be used according to the terms and conditions of said license. Use of all other works requires consent of the right holder (author or publisher) if not exempted from copyright protection by the applicable law. 


\section{(6) \\ UNIVERSITÀ DEGLI STUDI DI TORINO}

This is an author version of the contribution published on:

Questa è la versione dell'autore dell'opera:

Comparative Education, volume 51, issue 3, 2015, http://www.tandfonline.com/doi/full/10.1080/03050068.2015.1033249 ovvero Monica Mincu, The Italian middle school in a deregulation era: modernity through path-dependency and global models pp. 446-462

The definitive version is available at:

La versione definitiva è disponibile alla URL: http://www.tandfonline.com/toc/cced20/51/3 


\title{
The Italian middle school in a deregulation era: Italian modernity through path-dependency and global models
}

\author{
Monica E. Mincu ${ }^{1}$ \\ Department of Philosophy and Educational Sciences, University of Torino, Italy \\ Via Gaudenzio Ferrari 9/11, Torino, 10124, Italy \\ Tel.+39.0116703164; monica.mincu@unito.it
}

\begin{abstract}
At a time of intensified moves towards deregulation, the configuration of the Italian middle school and its relationship to education governance is of a peculiar type. Historically, it represents a unique example of the successful 'decision making' of the welfarist era. Though with some internal constraints, at the end of the ' $70 \mathrm{~s}$, it proved to be a progressive step forward in the context of schooling of that time. At present, the internal institutional processes and path dependencies contributed to render its comprehensiveness rather formal and weak. I will argue that partial deregulation is a major source of inequalities at the middle school level, engendered by both new and old mechanisms. Thus, partial deregulation further intensifies path-dependencies such as selective and academic patterns in education. In this sense, this analysis will show how global deregulation trends meet local and enduring path-dependencies.
\end{abstract}

Key words: comprehensive school type; Italian education; deregulation; teacher's perceptions. Introduction

Over the last 30 years, Italy has been involved with the welfare state building along the lines of other Southern European countries. In this context, during the 60's and the 70's Italy expanded universal education through a unified middle school as comprehensive provision. Since the ' $80 \mathrm{~s}$, neoliberal politics triggered deregulation consequences initially in various Italian welfare state arenas (e.g. health and insurance) which subsequently intensified in the education field as well.

Comparative scholarship suggests that it is hopeless (and maybe worthless) "enterprise to try and map every single local understanding of globally travelling myths" (Schulte, 478). At the same time, the thesis that "regional variations have actual significance as autonomous phenomena in their own right" (Schwinn, 2012) has to be acknowledged. Therefore, single country cases are not to be seen as "internal differences within the global system" (530). The vicissitudes experienced by the Italian welfarist middle school in the context of growing moves towards deregulation stands out and speak for themselves. The Italian path to modernity is uniquely interrelated to patterns of external referencing and socio-political change. I adopt a socio-historical and path-dependency approach, complemented by an ethnographic case study, in order to illuminate how transnational pressures and local processes impact upon its specific current profile that much of the sociological and typological scholarship do not reveal. The Italian case reveals how global contextual changes reinforce selectivity oriented path-dependencies that redefine a key welfare-state institution.

The creation of the new middle school in 1962, fully effective after 1977, represented one of the most significant post-war political accomplishments (Ventura, 1998). Nevertheless, its role in promoting social equality and upward mobility is at present weakened by peculiar traits of the wider education system. Recent research (FGA, 2010; De Simone, 2011) suggests that the comprehensive

\footnotetext{
${ }^{1}$ E-mail: monica.mincu@unito.it
} 
school is in fact responsible for increasing social inequalities, which appear to originate at the lower secondary level.

Historical and comparative scholarship (Wiborg, 2009, 2010; Clarke, 2009; Amsing, Greveling \& Dekker, 2013) indicates reasons why the comprehensive school has been successful in some European countries but not in others. Other sociological studies have engaged with paradoxes and limitations (West \& Hind, 2006). In addition, this line of scholarship identified types of partial vs full/radical comprehensiveness and assessed trends of convergence and divergence in Europe, (Green, Wolf \& Leney, 1999; Janmaat, Duru-Bellat, Green \& Méhault, 2013). Against this background, the position of the Italian comprehensive school is more complex than is usually assessed by international scholarship. It holds a strategic position as an institution whose internal processes and outputs in terms of student achievement and subsequent track orientation profoundly influence the overall profile and efficacy of the Italian system of education.

The contemporary Italian scenario is not fully captured by political science concepts such as "Second Republic" (Parker, 2007) or "tentative neoliberalism" (Grimaldi \& Serpieri, 2012). The Italian governance is built on a hybrid type of devolution and centralised bureaucracy on the French model (Parreira do Amaral \& Dale, 2013). Therefore, I propose deregulation as a broad concept that helps both scholars and practitioners understand the way institutions work in a governance-oriented context. It does not postulate a diminishing role of the State, but a relocation and a disaggregation of its activities (Dale, 1997), greater school autonomy, and a shift from public to private funding, and from public to private school government (Schlicht-Schmälzle, Teltemann and Windzio, 2011). However, as Dale maintains (1997), international comparisons should engage with the role of the State, the market and the community, rather than with a crude public/private contraposition. In fact, the Italian model of financial devolution implies a strong State, a weaker market and a significant contribution from the community, especially from parents ${ }^{1}$. At a justificatory level, the Italian trends towards devolution and education markets as key components of deregulation are in line with a global "disillusionment with the national modernisation programmes of the post-war period" and a "loss of legitimacy of the welfare state in general" (Whitty, Power and Halpin, 1998, p. 132).

Although deregulation appears to be weaker in coordinated market economies, such as Italy, in comparison to liberal market economies (Hall \& Soskicze, 2001) Italian scholars documented significant deregulation moves in various areas. Thus, I will engage with those specific processes that eroded middle school as a major welfarist institution over the last 20 years. More specifically, the enactment of deregulation politics in Italy involved a reinforcement of a selective path in education and thus diminished the potential of comprehensive-universal education. This outcome shows how a global move (i.e. deregulation) becomes context-specifically appropriated in a Southern European context, in line with seminal comparative scholarship undertaken by Schriewer (e.g. 2000, 2003; with Caruso, 2005). The voice of some middle school teachers is indicative of a specific institutional culture as produced by the current system's modus operandi and of social actors' expectations that parallel path-dependencies.

\section{Global modernity arena and referencing}

A comparative analysis of educational institutions necessarily engages with global policies and local reception and re-making processes. The comparative endeavour has strived to make sense of the interweaving of seemingly contrary currents (Schriewer, 2000, 327) of "internationalization" vs "indigenisation", "global diffusion processes" vs "culture specific processes". A transnational diffusion of models is a significant dimension and explains how the global is locally construed.

Thus, comparative education theories may help to understand the Italian middle school in its context, which is at the same time local and global. One theory is the "the arena model of global modernity" recently put forward by Schwinn (2012, p. 532), for which the referencing process between various entities does not necessarily lead to convergent outcomes. The global is to be understood as an arena in which a variety of developmental paths and patterns of social order may 
manifest. Multiple modernisation routes are speaking for themselves and therefore these may be worth investigating in their own. Another relevant suggestion is that a globalising potential may manifest in certain areas and alter the context for all the others. In his words, "modernisation initiatives taken by particular countries galvanise the elites of other regions into action" (p. 531). Another perspective is the above mentioned socio-historical work of Schriewer (...), that helps to understand how global and local dynamics are intertwined through processes of externalisation to world situations. In this sense, it is all the more significant that Italian academics backed their reform ideas with references to England or to an Anglo-American modernity model perceived as "most advanced".

In order to show the inception and the subsequent increased incoherence and disarticulation of the Italian middle school the idea of policy path fits particularly well the Italian case. From this perspective, new events at the global or local level may be assimilated by institutions working in a specific policy path, or, alternatively, these may start to disarticulate (Torfing). The interplay between transnational phenomena and local outcomes is usually investigated through reference relations analysis, translation processes and disposal over resources. Recent studies deal with translation dynamics (Schulte, 2012), others with policy referencing (Waldow, Takayama \& Sung, 2014). I will show how externalization and referencing are key mechanisms to Italian modernity and then engage with the current profile of a welfarist institution, in an increasingly unequal context. As main provision of comprehensive schooling following the primary school level, the Italian middle school should be seen as key institution at the interplay of exogenous (national and global) and endogenous (educational) factors, within its larger socio-economic context and deeply influenced by a flow of sedimented and new ideas. Therefore, I distinguish between an articulation phase regulated by a comprehensive path-shaping introduced since the 60 's, followed by a period of increased disarticulation in which a selective mode as enduring path-dependency is re-affirming also under the impact of a neoliberal context.

\section{From the "two people" political culture to the articulation of a welfarist institution}

This section analyses the historical roots of the original selective path, effectively captured by the Italian scholarship as the "two people" political culture. At the same time, I engage with the historically long transition to a comprehensive education The original binary configuration of the education system, as a two-track secondary school with classical-humanities and technical-scientific types, aimed to prepare "two different castes, to raise the aristocratic drones and the working bees" (p. 28), in the words of the minister of education, Correnti, in 1870. This position illustrates a founding 'two people theory' that largely influenced both progressive and conservative political actors (Semeraro, 1998). In fact, at the time of Italian Unification (1864), even moderated political forces accepted the status quo: "educating the people no more than is necessary, within the limits of possibility" (Ragazzini, 1990, p. 27).

The seeds of a comprehensive path go back to 1908, when the Bianchi Royal Commission advanced a proposal for a new unified lower secondary school. This was, however, only a simplification of the existing pipe-like structure, since the choice was still to be between the popular course, a dead-end track, and this new lower secondary school. Different rationales led to an ambiguous convergence of positions, still favouring a selective line. In fact, socialists and the national federation of scuola media teachers (Ambrosoli, 1982) were principally interested into primary and professional schools that were of immediate concern to the masses, and not into a common middle school. Consequently, their orientation reconfirmed the subaltern position of these categories. The proposal was not approved, and in spite of its imperfect design, represented a historical precedent for the years to come.

The Gentile fascist reform fully consolidated the selective path in the form of a pipe-like hierarchical system built around the liceo as academic track. As in the French case (see Cummings, 2003), the academic school played a leading role that deeply influenced the whole system. The 
puzzling separation of pipe-like tracks perfectly matched social groups: liceo for the élites, technical institutes for the urban bourgeoisie, other post-elementary school types for rural and lower urban proletariat, and finally, a liceo for middle class girls. Most significant, increased selectivity, an accentuated difference between technical and classical studies, and rigorous school entry requirements would have deep and longstanding consequences fuelling an academic pattern still visible at different levels and in many ways.

With the transformations of the fascist state, some idealists expressed their disagreement with this reform, the Catholics criticised the overwhelming presence of philosophy. Contextually, Gramsci denounced the accentuation of social differences, the failure to coordinate with modernisation processes, the downgrading of science and the upholding of a new verbalism and outdated humanism. Subsequent minor changes moderated its selective trait in favour of the lower and middle classes, the social base of the fascist regime. In 1940, a 'unique middle school', bringing together only those tracks leading to university studies, reduced the number of choices to three. The Latin language continued to preserve its tracking role from inside this school structure.

During the 1950s, teachers' unions, especially those linked to the major Christian Democratic Party, also played a relevant role in negotiations to introducing comprehensive schooling. An elementary teachers' union, the AIMC [Italian Association of Catholic Primary School Teachers] initially opposed the creation of a comprehensive middle school. In their view, a post-elementary school was in a better position to guarantee employment opportunities for elementary school teachers. For similar corporatist reasons, the UCIIM [Catholic Union of Middle School Teachers] was in favour of the creation of a unitary middle school with three specialisations (Semeraro, 1996). This process is a clear example of enduring pressures that remained powerful to present days. First, intellectual unemployment has been a constant pressure on the education system. Second, the Catholic political 'archipelago' lead through time the political debate.

In 1962, minister Gui supported the creation of a middle school. After only three years of discussion of different proposals on a new middle school (as internally diversified in tracks or as a unified cycle), the most radical proposal formulated by Communist Party was gradually endorsed and finally won (Ventura, 1998). Socialists and Christian Democrats actively sought a consensus, facilitated by a post-war era characterised by the quest of broad political agreements and played a decisive role as in other European contexts (Wiborg, 2009).

The lower secondary school was, for the first time, part of compulsory education, which implied the elimination of school choice at eleven. However, relevant traits of the previous selective path mitigated, for a while, its progressive potential. These were the marginal role assigned to not strictly academic subjects, the lack of implementation of full-time schooling and the retention until 1977 of Latin as an elective which skimmed and oriented the socially advantaged toward classical studies. In addition, two different tracking measures - for pupils with lower achievement levels and for 'socially maladjusted' and disabled students have been in place until 1977.

The historical context sketched above proved to be exceptionally favourable for the creation of a common middle school ${ }^{2}$. A unique window of opportunity opened. Some characteristics of the foundational selective path such as 'part-time schooling' (short daily schedules) especially in less populated and non-urban areas, and a curriculum profile as academically oriented and pedagogically regulated by an idea of knowledge transmission and curriculum 'coverage', would prove to be exceptionally time resistant. Structural issues linked to transition points before and after the middle school strongly resisted through time. To sum up, two major equity reforms - the introduction of the middle school (1962) and the liberalisation of university access (1969) significantly mitigated the selective character of the Italian system of education as a whole and created a favourable context for comprehensive education. However, the articulation of the new comprehensive path encapsulated the above-mentioned traits from the "old" selective path and continued to carry the trace of it. A complete dislocation of the original selective path couldn't be reached. 
In order to investigate the Italian specificity, both structural and cultural rationales are to be carefully considered (see Schwinn, 2012). A glimpse into the political culture and the dynamic of externalisation and referencing processes will also consent to link this Southern European State to its wider global political environment.

Italian modernity and Anglophilia as major reference

In this section I will describe the Italian modernity with the help of its long-lasting political culture. At the same time, this section locates Italy and Italian education in a transnational web through processes of externalization to world models. Since the nation formation, discourses of modernity are imbued with a major political myth of the "two Italies": the North vs. the South, the city vs. the country, the Church vs. the State, modernists vs. traditionalists, engagement vs. "qualunquismo" (anti-politics), the "legal" country vs. the "real" country, and right vs. left. In addition, the existence of these oppositions is not an exclusive Italian development. whilst their intensity it is so (Parker, 2007, p. 7).

Moreover, an Italian exceptionalism encapsulates the assumption of non-reformability, also of the educational system. Both are discursively intermingled with the national identity question and the Italian modernity issue, and mostly perceived as weak (Patriarca, 2001, p. 24) or incomplete. References to the incomplete character of the Italian modernisation process lead to a "normalisation" thesis: "Italy must become a normal country". The normalisation political myth supposes references to a superior and unreachable "Anglo-American" model, which constantly informs public discourses (Ginsborg et al. year p. 188),

The Italian road to modernity have always implied comparison to other European nations and a negative and stereotyped account of the Italian identity (Patriarca, 2001). Moreover, the search for models is a constant in this debate. The English model or Anglophilia is a very important point of reference for Italian liberals since Risorgimento and the post-unification period in the building of Italian democracy (Cerasi, 2002). A "getting closer and moving away" dynamic from the "paradigmatic English model" is constantly at work. While references to France and Germany were more pragmatically oriented given their proximity and appropriateness, the English case was widely recognised as being unapproachable. At first glance, it played the role of a "mirror of ideology, or a screen on which ideal plans for society and its institutions could be projected" (Cerasi, 2002, p. 7). However, at a closer analysis, in their appreciation of English self-government, Italian liberals unveiled conservative desires to preserve social hierarchies. While discourses on the English model were formally intended as a project of modernity, on practical grounds and mainly after the 1880s they served the antidemocratic purposes of the local and liberal elites (Cerasi, 2002).

The historical precedents of Anglophilia in the political realm shed light on contemporary pedagogical discourses related to the structure and functioning of the education system as forms of imagined globalisation (Steiner-Khamsi, 2004) and modernisation. Over the last decades, references to England as a model of governance play, once again, a symbolic function serving to legitimise internal developments and broadcasting its alleged merits to the world. References to OECD have come forefront, as it is the case elsewhere. However, these have not supplanted the more consolidated Anglo-American reference, and this is somehow in contrast to Lingard's prevision about a prominence of the OECD referencing (2001 in Waldow, Takayama \& Sung). In fact, in Italy the OECD hero, that is the Finish education, is not as much as a policy reference. England remains a major reference, particularly in key reform fields such as teacher training (Mincu \& Chiosso), teacher professionalism (Cenerini), school choice and academies/charter schools (Ribolzi).

Academics and related associations (TRELLLE, ADI etc) are typical carriers and translators of global policies. For instance, TREELLLE Association is an independent think tank organisation composed by academics and policy makers that played the role of an active translator of the OECD devolution proposals. Some catholic and right wing sociologists have been most interested into 
theories of school choice and devolution and picked up from the English and American cases. Some clear examples about the importance of the English model seen as most worthy to confront with are to be found in the field of initial teacher training reform (Mincu \& Chiosso, 2009) and in the personalisation policy (2003-2009), the latter a case of isonymism that aimed to revitalise a specific Catholic vision in education (Mincu, 2012).

\section{Persistent inequalities at a time of drifts towards deregulation}

In this section I show how a new institutional context represents a major exogenous factor which explains how the middle school works at a time of increased deregulation. Significantly, Italy belongs to a Southern European welfare-state typology, in line with a fragmented model that characterises conservative-corporatist countries. The most significant characteristic of the Italian welfare state model lies in its particularistic-clientelistic nature, which paradoxically implies polarisation and social class stratification, with a significant role assigned to families (Ferrera, 1996; ..\&.. 2003) ${ }^{3}$.

At the same time, the Italian political culture and its traditional long-lived political subcultures have set the scene and significantly influenced the possibility of education reform, and its direction. These were, in the 1980s, the 'white' Catholic constellation, the 'red' Socialist and Communist world and the secular charismatic populist milieu of the 1990s. The Church versus the State continued to be one of the major tensions at work (e.g. Semeraro, 1996; Ventura, 1998). In fact, intense political controversies between political parties on education matters have been a major barrier to reform (lapsed or missed reforms for Benadusi, 1989).

Among the most acute challenges that impact upon equality of opportunity in Italy are regional differences, as revealed for the macro-regions of South and Centre-North by Checchi and Peragine (2005), inequality in school completion rates, relevant early school-leaving levels and year repetition. One of the most enduring challenges over the last thirty years has been the persistence of unequal access to higher secondary school as a self-selection mechanism at the completion of the comprehensive education. In fact, the transition from the lower to higher secondary education is in line with the original selective path, assigning the track choice responsibility to families. Subsequently, if decisions prove to be based on "too high" aspirations, a mechanism of reorientation towards less prestigious structures will stream down the pupils, whilst upward mobility is most unusual. At the higher secondary level, stratification between school tracks reaches peaks of 100 and more PISA points between the more demanding academic liceo and less prestigious professional schools. ${ }^{4}$

Italian centralisation has been considered of a "harlequin type", which implied significant margins of diversification (Semeraro, 1996, p. 221). In fact, the institutional context in which the Italian comprehensive school operated has been characterised by moves towards diversification since the very beginning, that is the 'experimental period' initiated in 1977 and lasting throughout the 1990s. Their legitimation was related to a need to counterbalance a highly bureaucratic system. At this early phase, higher secondary schools have been entitled to diversify their curriculum profile as types of specialist schools. From the 90's onwards, a deregulation phase has been more clearly in place with a major school-autonomy reform. Influential Catholic groups endorsed liberal and neoliberal arguments and allowed for more involvement of local communities and families (Semeraro, 1996).

Unquestionably, a clear hallmark of a renewed institutional context is the major federalisation State reform under way since 2001, with a change in the Fundamental Law (the $5^{\text {th }}$ Title). Linked to this, the school autonomy reform of 1997, various neoliberal initiatives and recent fiscal federalisation in education (FGA, 2010) are concrete steps towards a partial deregulation, which Semeraro (1998) traced back to the beginning of the '90s. The federalisation of education 
(Bordignon and Fontana, 2010) as process of financial and institutional decentralisation at the regional level is silently in place - by abandonment - and, as an intentional process, it is said to be imminent, after years of indecision and lack of public discussion. Linked to that, a long-standing economic stagnation and the financial and economic crisis after 2007 led to a significant decline in the budget that the Ministry of education directly assigns to schools (dotazione organico). On average, the foreseen needs of a school as stated in their balance sheet are $35 \%$ higher than their resources, which indicates an incomplete realisation of their planned curricular offer (Granello, 2010).

In such a reconfigured context, the Italian middle school still represents a key academic stage where students are oriented towards one of four academic tracks of upper secondary education: general upper secondary school, technical school, vocational school, and a vocational education and training system which is regulated at the regional level, outside the public system of education. What is clearly visible from the historical account is that culture specific patterns of thought, material resources and historical preconditions continue to deeply influence the way national/local élites respond or filter transnational ideas and myths. In the next section, my analysis will engage with those endogenous factors and current system properties that contribute to understand the tensions at work.

\section{The disarticulation of a welfarist institution}

In this section I will tackle new developments in education, both internal and external to this institution, at work since its creation or recently added that strongly question its comprehensive profile.

From the outset, it is important to note that a new form of comprehensive institution has been promoted over the last 15 years (istituto comprensivo). This implies that individual schools are unified from an administrative point of view while they continue to be physically separated and distantly located ${ }^{5}$. Thus, several pre-school structures, elementary and middle - lower secondary schools may be linked at vertices by a single head-teacher and administrative structure. Such territorial aggregation of a variable geometry does not consider quantitative issues in terms of student population and their effective possibility to continue at higher levels in the same institution, nor more substantial issues of a necessary vision and mechanisms of continuity. There is broad agreement that such administrative changes have been mainly led by managerial territorial reasons of financial cuts to school staff. While the decision to cut down the finance may find some grounds for justification, the comprehensive principle is serving mostly purposes of legitimation. Such a contradiction, of which some teachers are acutely aware of, must be understood as a case of isonymism. A "comprehensive" idea stays for mere administration restructuring.

A global trend towards diversification has been intertwined in the Italian case with a local and most debated policy issue, that is the recognition of the private Catholic schools as part the public system of education. These became eligible for public finance (Law 62/2000). The officially recognised paritarie schools - equally considered schools - sector is roughly $24 \%$ of all schools with $10 \%$ of the overall student population (40\% pre-primary, $9 \%$ primary, about $8.6 \% \%$ for lower secondary schools, and reaches $23 \%$ at the higher secondary level). Paritarie schools charge fees that middle class parents can afford and may also provide free places or lower fees for those in difficulty, depending upon the amount of public funds allocated to this end in the form of school vouchers. While this development is in line with what happens in other European countries (see France) it intensifies the overall diversification and school choice in education. Though private schooling remained stable over time, scarcity of public resources continued to fuel one of the most enduring conflicts. Scarcity of resources and related conflicts are one cause of possible destabilisation of the public school as a whole.

The above-mentioned developments further document the access opportunities in a system lacking school zoning politics. The same possibility of choosing at any time a different public 
school, based on its perceived status as a less demanding or more protective context, is significantly at work. Almost $80 \%$ of the head teachers in a study by Musset (2012) reported that there are two or more lower-secondary schools (and almost 90\% reporting at least one school), including privateparitarie, competing in the same area. Notably, Italy ranked $5^{\text {th }}$ out of 34 countries in terms of number of alternatives available in a given territory, just before the United Kingdom ${ }^{6}$. This market like scenario is a relevant external factor that diminishes the comprehensive potential of the middle school.

Universal provision has been ultimately eroded by growing financial disparities. The increased financial difficulties of the public schools to offering longer free school attendance implies that comprehensive middle (and elementary) schools operate with different schedules, based on their location. Some middle class parents may choose to pay for integrative activities in paritarie rather than in a public school, given that many of the latter cannot offer state-supported longer schedules. Other parents may be constrained to stick with the local public school and to pay fees for services that used to be public until recently, such as longer daily schedules, in particular, or expensive school meals as related to parents' incomes in some large metropolitan areas ${ }^{7}$. It should be noted that state finance is not equally distributed at the regional level - with the Northern areas receiving substantially more finance from the State, and the Southern regions from the European Union - nor between school levels, with the lower secondary schools, that is middle schools, at the lowest level (56\% of State finance, see Granello, 2010). Thus, partial deregulation of the school finance linked to diminishing resources (Granello, 2010) and a severe reform that reduced the school schedules and the teaching staff (Bordignon and Fontana, 2010) further intensify the role of the family. From a traditional clearing house (Ferrera, 1996), the Italian family is now said to be a major sponsor of public school.

Moreover, the global politics of school autonomy represents a push towards greater diversity and specialisation within the public field and particularly in urban areas. In fact, the PISA mean scores show that the degree of the school autonomy has been rising from 10.9\% (2000), to 59.3\% (2003), 58.4\% (2006), illustrating quite high levels of pedagogical and curricular autonomy, increased financial autonomy and quite low levels of autonomy on staff policies (less than 10\%) (Schlicht-Schmälzle, Teltemann and Windzio, 2011).

The outcome induced by a context of increased deregulation is that the current lower secondary school is found responsible for increasing social inequalities. As showed by FerrerEsteban (2011) inequalities of process and school outcomes, such as precarious employment of teachers, students' allocation across schools, and student distribution across classrooms as informal tracking are significantly at work. Ethnic stratification characterises urban schools, where branch schools are mainly composed of lower classes, in a historical stratification - once Southern Italians, now pupils of immigrant backgrounds (Ciafaloni et al, 2007). This study reveals informal processes of denied admission, traditionally regulated at the local level by the single school. The possibility to request enrolment at the school level is responsible for the covert selection of students and this has a negative impact on comprehensive provision (West, Hind and Pennell, 2004; West and Hind, 2006).

The above-mentioned issues are new effects of a selective path that is currently reinforced through deregulation moves. However, as mentioned earlier in this article, other significant traits continued have been at work since its institutional inception. One traditional factor is the constant staff turnover at the school and classroom level which negatively impact less able and vulnerable students (see Ronfeldt, Loeb, \& Wyckoff, 2013) ${ }^{8}$. Also at the middle school level, contract teachers move between schools on a yearly or even monthly basis, while permanent staff may request relocation at any time as a self-selection process. The student flow between schools and classes is also a dysfunctional trend that further intensifies the high instability at the school level produced by teachers turnover (Barbieri, Cipollone and Sestito, 2007). The presence of transition points represents another enduring trait of a selective path: a first transition from the elementary to the lower secondary, and from this latter to higher secondary. In the second transition at 12-13 years old, a decision is already made in most cases, one year before the completion of the lower 
secondary school. By January of their third year, 9 months before the beginning of senior school or VET, pupils are supposed to officially request enrolment. Mocetti (2011 in De Simone, 2011) also puts forward the thesis of an even earlier choice, given the experience of irregular course studies that may influence the next transition and further delays. This shows that a selective mode worked from inside a comprehensive path for a while. It is reasonable to conclude that in the current phase, stratified endogenous and exogenous factors reached a critical mass of selective characteristics that significantly eroded the welfarist institution.

To sum up so far, a vision of a "two people political theory" dominated the Italian system of education since its origins and variously legitimised a selective and stratified configuration. The creation of the common middle school in 1962 represented an important step forward to overcoming such a selective and dualistic configuration. This institution rebalanced the system and introduced comprehensive schooling. Later pushes towards more diversification, both bottom-up and top-down, increased school autonomy, financial decentralisation and economic cutbacks have further reinforced the role played by the Italian families, both in cultural and financial terms. The transformations of this welfarist institution under a global push towards deregulation currently reinforce a selective mode, which proved to be an enduring path-dependency. The next section will consent a glimpse into teachers' representations and expectations.

\section{A middle school portrait}

In line with my theoretical framework, ideas of how this institution is conceived of, and how it contributes to shape the actors identities are tangible in a "lived reality". Contemporary middle school, as much as its wider institutional contexts, offers "a cognitive template to its actors" (Hall \& Taylor?) worth investigating along the lines of a selective versus comprehensive ethos. An ethnographic account of a case study vividly illustrates organisational and structural issues, based upon actors' representations. This case study represents a convenient sample and the choice is justified by its insertion in a mixed/patchy social neighbourhood, common to most urban areas. It proved however to offer a privileged angle of observation of an urban institution, determined to achieve renewed reputation. Teachers characterise their institution as a somehow specialist school, through its musical education programme and the presence of additional teaching staff dedicated to special education, less able and lower achievers. For these reasons, the official profile of this institution appears, on paper, as particularly in line with a protective, inclusive and comprehensive ideal. The main method has been participant observation with the collection of field notes ${ }^{9}$.

The Scuola Media Statale Dora (pseudonym) is located in a good neighbourhood. Nevertheless, this area reflects a typical patchy pattern that depends upon the prestige and economic value of buildings. The school is located in a green zone, close to a river, but surrounded by popular blocks of flats. Its 'intake' can be characterised as lower-middle and working class pupils. A range of nearby public middle schools is available. In the past and quite significant, teachers nurtured sentiments of opposition towards a neighbouring competitor public school, which was perceived to be for better-off families. The student composition is largely of Italian nationals, with few students of immigrant origins. Regarding its reputation, teachers declare that it is the "right place" for disabled pupils since they have many specialists. At the same time, and not so paradoxically given the Italian practices of grade repetition, it shows the highest rates in the area for year repetition. Under the leadership of its newly appointed head teacher, the staff is supposed to reverse this tendency. A programme of music as elective is mentioned as specific curriculum specialism.

This middle school is formally linked to an elementary school under the umbrella of a comprehensive institute. The schools are not co-located, and progress from one to the other is not automatic, so parents may also choose between other public schools in the area. The degree of institutional integration between primary and lower secondary is relatively weak, although 'commissions of continuity' are usually in place through formal meetings at the first transition point. 
As indicated, a major organisational pattern allows for a 'double choice': both between public schools and towards private schools. From discussion with teachers, it is evident that the Dora middle school receives pupils from other schools in the area at any point of the school year (inward flight) for reasons of misbehaviour, lower achievement and other social problems. An outward flight of students is less frequent. Private alternatives in the area are also available, given its strategic position. This finding is also indicative of the endemic instability of the teaching staff and the pupils. Almost 30\% of the teaching staff in Dora are untenured, which implies different pay and working conditions, and most relevant, high instability on an annual basis.

As common practice, at the beginning of the first year, teachers dedicate substantial effort to organising the new classes with the declared aim of a fairly heterogeneous distribution of pupils within classes, mainly based on their previous achievement results. However, teachers declare that they base their decisions on discussions with primary school teachers (when pupils continue their studies in the same comprehensive institute) to gain information on behaviour issues, socialisation patterns and other criteria, and this considerably broadens the official position. In fact, from interviews, it appears that teachers try to accommodate socialisation patterns already in place between families. Another issue is grouping by ability inside and outside the mainstream classes with or without special education teachers. From classroom observations, special education teachers systematically divide pupils and choose spaces outside the classroom for differential lessons. This is ostensibly considered an opportunity that the school offers to families and not a critical issue.

Teachers in this school are in their fifties and sixties, which reflects a generally stable pattern of a relatively older Italian teacher workforce ${ }^{10}$. Their professional narratives are strikingly similar in that the teaching profession was invariably a second choice, a fall-back career. Some of them admit that in their early years they did not enjoy teaching, but that over time they came to care about their pupils. An 18-hour teaching job as a public employee, for a relatively low salary, is paradoxically one of the strongest motivations to enter the profession, especially for women in the Italian economic scenario. In many cases, secondary school teachers may hold a second freelance job, to provide additional income. Most conversations indicate that teachers lowered their occupational expectations and perceive their current profession as socially less desirable. Unsolicited remarks about their children and family life frequently refer to liberal professions as more prestigious.

It emerges that teachers work within separated sections (vertical class organisation 1st, 2nd, $3^{\text {rd }}$ grade $\mathrm{A}$, for instance) within a specific team and that wider collaboration between sections is uncommon:

We create the sections; but in some sections I would never work, never, not even if...I would rather start crying; because in those sections I don't find an understanding of how to deal with disabled pupils. (special educational needs teacher)

The most relevant social problem in this school, as reported by one teacher, lies in the family structure, and the excerpt below is indicative of the socio-economic background of this school. In addition, some teachers denounce a lack of concern for their students' personal issues at a critical age and the culturally performance-oriented and evaluative approach held by some of their colleagues.

Problematic students are those with families in difficulty, $75 \%$ are single parent families; the teenagers have emotional problems, they are left alone at home, their parents have joint custody; they never go out, live with their video games, their lexical area is limited, they lack curiosity ..... which is supposed to be developed when you are a child, playing...(special educational need teacher)

Teachers' views on the role of the middle school emerge easily from unsolicited remarks and from informal conversations and are variously critical of the status quo. Quite significantly for a 
selective path-dependency relevance, one special education teacher advances a more stratified solution:

... if I was to be prime minister, I would bring back the middle school as it was, different for those who may not want to study....they can learn to do something practical, I would focus a lot on the didactics and more on the laboratories. (special educational needs teacher)

Their views are clearly informed by learning processes in their institution based on considerations on the social justice ideal represented by the comprehensive school and rationales derived from its organisation. Their views are also informed by their sense of belonging to a social class and their political opinion about the role of public schools. Low expectations are at work while assuming that lower achievers are an obstacle

As it is structured nowadays, [the middle school] tends to level everybody down. At 13 and 14 years old all the young people are equal and should have the same rights and duties...but they are not equals and they should privilege their training, their self; if they want to study, for instance my kids....they have to study; to cultivate this I had to put them in a private school. The public school is a splendid school, but there are many cases [pupils] that hinder calm implementation of the curriculum. (special educational needs teacher)

On the other hand, their view of the perceived failure of Italian middle school is based upon their strong opinion that the curriculum is too academically oriented and demanding ${ }^{11}$. When asked how they value the proposal of comprehensive schooling up to 16, the answer hints at an excessive rigidity in the curriculum organisation:

to continue for another two years, making them learn history, geography...if you think about that, at 11, 14 years old, they spend all their morning sitting on chairs....they spend all their morning seated. (special educational needs teacher)

This teacher assumes that there are mainly limits to her autonomy in organising school activities. Another teacher is, however, fully aware that a lot is up to her and actually she admits to making full use of her freedom to avoid an academic approach (livresque in her words) based on books and curriculum prescriptions. Their views of the teaching profession are indicative of a paradoxical de facto autonomy in a highly bureaucratic system. Such diversity of perceptions has been historically identified as a key hallmark: "it is quite difficult to find a unitary project approach even within the same school and it is often the case that the school from the lower floors ignores what happens at the higher floors." (Semeraro, 1996, p. 222).

From participant observations, one teacher proves to be an engaging teacher, particularly creative in conducting stimulating class discussions. At the same time, she was concerned about issues of socialisation and labelling between pupils themselves. Her views are however not positive about the possibility to work for equity at this school level, and this "cognitive template" reinforce a selective path as culturally reproduced by the actors of this same institution

Working on motivation with those who don't want to study is difficult; but it is possible to work on practical issues, on this you can work. But on the motivation to study, you know, if they were children of 7, 8 years old [it would have been possible].... at 11, 12, with grade repetition as a career record it is a bit difficult to work on motivation. (special education needs teacher) 
Though limited in time and by the number of actors observed, this ethnographic account proves to be extremely powerful to sketch an institutional context. First, these actors have strategies in line with their perceptions of what can be achieved under the current circumstances. They continuously refer to those who want to study and are already motivated and those who do not in terms of two distinctive groups, somehow paralleling the "two people theory". Second, the academic orientation of the curriculum as long-standing path-dependency is apparent, as well as various selective practices and ideas that imply pupils' concentration and stratification, based on their abilities or social class. A convincing argument that has the potential to explain the Italian case and its drawbacks of a more equitable provision in education is that "development follows, rather, a given path in accordance with cultural legacies" (Schwinn, 2012, p. 534). Though not deterministic, such cultural legacies are particularly strong as in the teachers' representation of their mission and the expectations linked to this institution.

\section{Conclusions}

Domestic processes of change and path dependencies are also effectively captured by historical new institutionalism (Torfing, 2001). In contrast to sociological new institutionalism, usually accused to emphasise homogenisation and to neglect contention between actors with different interests (Schriewer; Caruso, 2008), historical new institutionalism focuses of power relations that shapes institutions in context. In addition, it fuelled the varieties of capitalisms approach (Hall \& Soskice, 2004), very much in line with a global modernity arena (Schwinn, 2012). At a time of increased diversification of the educational arena, both conflict over scarce resources and the role of the family as a clearinghouse are increasingly at work. As is the case of social services, education shows a mix of universal provision and stratified usability (e.g. the relevance of the location). Global deregulation moves go together with a perceived failure of State administration and a lack of trust in public services. Modernisation by models fuelled a neoliberal alliance in favour of school autonomy and diversification with the recognition of paritarie schools as part of the public area. The result has been a more diverse - 'open' system, in the absence of further clarification as far as the role of the State is concerned. It can be argued that the Italian middle school only formally 'keeps together' pupils from eleven to fourteen, through a common curricular offer. Internal factors, such as path-dependent strategies and perceptions are favoured by external conditions of increased diversification and competition. Moves towards deregulation appear to strengthen selectivity. Therefore, various structural traits and broader system characteristics upset and dramatically reduce its scope towards an equity ideal

This key institution has been approached at the interplay of national and global factors, within its larger socio-economic context and under the influence of sedimented and new ideas. It is not easy task, not the aim of this paper, to assert how much politics shaped this institution and if actors' strategies and goals have changed from inside after its articulation as a key welfare-state institution. What appears from this socio-historical analysis is its long-standing selective path, that finds new grounds in a more deregulated and market-like school context. A key finding is that ideas play a crucial role in shaping actors' strategies and goals, e.g. the two-people theory, while references to world models, in particular the English model, mediated the reception of global policies. Cultural factors, such as the role played by families, are deeply linked to structural issues. From the ethnographical account, it emerged that teachers' mediate a path-dependant and cultural reproduction pattern. One of their key cognitive template is the perceived inability to change pupils' motivation and aspirations. Thus, the case of this institution is an emblematic case in point of Italian modernity that "speaks for itself".

Dr. Monica Mincu is a Senior Lecturer in Comparative Education, University of Torino and she holds the National Qualification as a Reader since 2013.. She has conducted historical and comparative research on Eastern European systems and teacher education. 
E-mail: monica.mincu@unito.it

\section{References}

Ambrosoli, L. 1982. La scuola in Italia dal dopoguerra ad oggi. [The Italian school from the postwar to present days]. Bologna: Il Mulino.

Amsing, H., Greveling, L, and J. Dekker. 2013. "The struggle for comprehensive education in the Netherlands: the representation of secondary school innovation in Dutch newspaper articles in the 1970s". History of Education. 42 (4): 460-485.

Barbieri, G., Cipollone, P., and P. Sestito. 2007. "Labour market for teachers: demographic characteristics and allocative mechanisms". Giornale degli Economisti e Annali di Economia. 66 (3): 335-373. Available at ftp://ftp.gde.unibocconi.it/gde_articles/2007/GDE_V66_N3_P335-373.pdf

Benadusi, L. 1989. La non-decisione politica [Political non-decision]. Florence: La Nuova Italia Editrice.

Bertola, G., Checchi, D., and V. Oppedisano. 2007. "Private school quality in Italy". Giornale degli Economisti e Annali di Economia, 66 (3): 375-400.

Bordignon, M., and A. Fontana. 2010. Federalismo e istruzione. La scuola italiana nell'ambito del processo di decentramento istituzionale. [Federalism and education: The Italian school and institutional decentralisation]. Torino: Fondazione Giovanni Agnelli. Working Paper. Available at http://www.fga.it

Ciafaloni, M., Demartini M., Ghioni, J., Pantó, S., Ricucci, R., Sansoé, R., Valetti, R., and I. Zagrebeisky. 2006. Concentrazione e dispersione differenziale degli allievi stranieri nelle scuole di Torino. [Concentration and differential allocation of foreign origins pupils in schools in Torino] Comitato Oltre il Razzismo. Retrieved from: http://www.piemonteimmigrazione.it/site/components/linkjd=272\&cf_id=60

Checchi, D., and L. Flabbi 2007. "Intergenerational mobility and schooling decisions in Germany and Italy: The impact of secondary school tracks". IZA Discussion Paper. n. 2876: 1-65.

Checchi, D., and V. Peragine. 2005. "Regional disparities and inequality of opportunity: the case of Italy". IZA Discussion Paper. n.1874: 1-31.

Clarke, M. 2009. "Educational reform in the 1960s: the introduction of comprehensive schools in the Republic of Ireland". History of Education. 39 (3): 383-399.

Dale, R. 1997. The State and the governance of education: an analysis of the restructuring of the state-education relationship. In Education, culture, economy and society, ed, A. Halsey, H. Lauder, P. Brown and A. Stuart Wells, 273-282. New York: Oxford University Press.

De Simone, G. 2011. Render unto primary the things which are primary's. Inherited and fresh learning divides in Italian lower secondary education. Working Paper n. 44 (12/2011). Retrieved from:

http://www.fga.it/Uploads/Media/G._De_Simone_Render_Unto_Primary_The_Things_Whi ch_Are_Primary_146_S_-_Fga_Wp44_01.Pdf

Dobbins, M. 2014. "Explaining change and inertia in Swedish and French education: A tale of two corporatisms?" Policy Studies, http://dx.doi.org/10.1080/01442872.2013.875149

Ferrer Esteban, G. (2011). Beyond the traditional territorial divide in the Italian education system. Aspects of system management factors on performance in lower secondary education. Working Paper. Torino: Fondazione Giovanni Agnelli. Available at http://www.fga.it

Ferrera, M. 1996. "The 'Southern model' of welfare in social Europe". Journal of European Social Policy. 6 (1): 17-37. 
Fini, R. 2007. Education and social selection in Italy. In International studies in educational inequality, theory and policy, ed. R. Teese, S. Lamb, and M. Duru-Bellat, vol. 2, 89-110. Dordrecht: Springer.

Fondazione Giovanni Agnelli [FGA].(2010). Il rapporto sulla scuola in Italia 2010. [Report on the Italian school 2010]. Laterza: Roma-Bari.

Granello, S. 2010. Il bilancio delle scuole, questo sconosciuto. [The school balance sheet]. Torino: Fondazione Giovanni Agnelli.

Green, A., Wolf, A. and Leney, T. (1999). Convergence and divergence in European education and training systems. Bedford Way Papers. London: Institute of Education.

Grimaldi, E. and R. Serpieri, 2012. "The transformation of the education state in Italy: a critical policy historiography from 1944 to 2011”. Italian Journal of Sociology of Education. 1: 143180. Available at http://www.ijse.eu/index.php/ijse/article/view/133/135.

Lareau, A. 2003. Unequal childhoods: Class, race, and family life. Berkeley, CA: University of California Press.

Megahed, N., and M. Ginsburg. 2008. Social inequalities, educational attainment, and teachers in Egypt. In Inequality in education. Comparative and international perspective, ed. D.B. Holsinger and W.J. Jacob, 369-391. Hong Kong: Springer.

Mocetti, S. 2012. "Educational choices and the selection process: before and after compulsory schooling”. Education Economics. 20 (2): 189-209.

Musset, P. 2012. School choice and equity: Current policies in OECD countries and a literature review, OECD Education Working Papers, No. 66, OECD Publishing. Retrieved from: http://dx.doi.org/10.1787/5k9fq23507vc-en

Nicolai, R. and A., West. 2013. School type and inequality. In Contemporary debates in the sociology of education, ed. R. Brooks, M. McCormack, and K. Bhopal, pp. . New York: Palgrave Macmillan.

Parreira do Amaral, M., and R. Dale. 2013. Governance of educational trajectories. Project: Governance of educational trajectories in Europe (GOETE). Thematic report. Retrieved from: http://www.goete.eu/

Parker, S. 2007. "A tale of two Italies - Continuities and change in the Italian Republic, 19942006". Modern Italy. 12 (1): 1-15.

Polesel, J. 2005. Change and the lapsed reforms: Senior secondary education in Italy. In International handbook on globalization, education and policy research, ed. J. Zajda, 717731. Dordrecht, Netherlands: Springer.

Polesel, J. 2006. "Reform and reaction: Creating new education and training structures in Italy". Comparative Education 42 (4): 549-562.

Polesel, J. 2010. "Educational outcomes, policy reform and cultural capital in Italian secondary schools". Comparative Education. 46 (2): 173-182.

Ragazzini, D. (1990). Storia della scuola italiana. Linee generali e problemi di ricerca. Firenze: Le Monnier.

Schizzerotto, A., and C. Barone (2006). Sociologia dell'istruzione. [Sociology of education]. Bologna: Il Mulino.

Schlicht-Schmälzle, R., Teltemann, J., and M. Windzio (2011). Deregulation of education: What does it mean for efficiency and equality? TransState Working Paper No. 157, Universität Bremen.

Schwinn, T. 2012. "Globalisation and regional variety: Problems of theorisation". Comparative Education. 48 (4): 525-543.

Semeraro, A. (1998). Il sistema scolastico italiano. [The Italian system of education]. Roma: Carocci.

Sestito, P. (2011). Indagini IEA TIMSS e PIRLS. Sintesi dei risultati. Retrieved from http://www.invalsi.it/areadati/pirls/2011/Sintesi_dei_risultati.pdf. 
Takayama, K. 2012. "Exploring the interweaving of contrary currents: Transnational policy enactment and path-dependent policy implementation in Australia and Japan". Comparative Education. 48 (4): 505-523.

Ventura, S. 1998. La politica scolastica. [Education politics]. Il Mulino: Bologna.

West, A. \& Hind, A. 2006. "Selectivity, admissions and intakes to 'comprehensive' schools in London, England". Educational Studies. 32 (2): 145-155.

West, A., Hind, A., and H. Pennell, 2004. "School admissions and <selection> in comprehensive schools: Policy and practice". Oxford Review of Education. 30 (3): 347-369.

Whitty, G., Power, S., and D. Halpin. 1998. Devolution and choice in education: The school, the state and the market. Buckingham: Open University Press.

Wiborg, S. 2009. Education and social integration. Comprehensive schooling in Europe. New York: Palgrave Macmillan.

Wiborg, S. 2010. "Why is there no comprehensive education in Germany? A historical explanation". History of Education. 4 (39): 539-556.

${ }^{1}$ In 2008, parents were the main private contributors with $14.7 \%$. The state contributed with $66.3 \%$, the regions with $3.8 \%$, the local institutions with $7.2 \%$ (provincial, municipal, other public), and a 35\% came from the UE (particularly the Southern regions) (Granello, 2010).

${ }^{2}$ Subsequent policy processes have been signed by stagnation as "political non-decision" (Benadusi, 1989) and acute intensification of the political contrapositions.

3 This is characterised by (1) income maintenance, as polarised protection offered by a wide range of agencies, (2) universal health care but a strong public/private mix, (3) the southern family as a social clearinghouse, (4) public institutions as vulnerable to partisan pressures and manipulations, political clientelism or outright corruption (Ferrera, 1996).

${ }^{4}$ PISA 2000 showed that "[t]he average score in high schools in North-Western regions was 572 against 503 in the South; the corresponding values for vocational schools were 473 and 398,respectively". Checchi and Peragine (2005, p.15).

${ }^{5}$ For instance, there may be 1 pre-school, 3 elementary and 1 middle schools or other local arrangements. These schools have been created in different moments and may have various traditions precedent to their comprehensive grouping.

${ }^{6}$ The OECD average for 2 or more choices was about $40 \%$ of head teachers, and for at least one school, $78 \%$.

${ }^{7}$ Municipalities manage educational services such as school meals. This implies that prices may widely vary with the financial situation of single cities and with parents' income, reaching peaks of 7/8 euro per day per meal for pupils with both working parents. This is perceived as unfair price since quality is low in some large urban areas, whilst pack lunch solutions are not allowed at lower school levels or in certain areas. Other school costs are also covered through families' contributions

${ }^{8}$ See Ronfeldt, M., Loeb, S., \& Wyckoff, J. (2013). How teacher turnover harm student achievement. American Educational Research Journal 2013 50: 4

${ }^{9}$ Informal discussion with 4 teachers after systematic lesson observations during a 3 month period of time, 3 of them of special education, in the same "section".

${ }^{10}$ Teacher education for secondary school has been traditionally provided on an ad hoc basis through a myriad of local and national solutions, including nationally organised selections and different parallel scrolling lists for people in possession of a degree. Thus, their pedagogical professional training is quite different, ranging from no initial training to an ad hoc or special programme. Two of the interviewees hold a special education qualification and their work should be with the class as a whole. In practice, their work involves mostly ability grouping in the classroom setting and more frequently outside.

11 The 34 hours a week include not only 9 hours of Italian and humanities, 6 of maths and science, but also technology, music, physical education, English and a second European language. However, teachers complain of an academically unbalanced offering, a clear undervaluation of practical and manual activities and insufficient hours of physical education. At the same time, teachers' autonomy on curriculum matters appears as more significant, at least on paper, under a national curriculum regime. As a rule, the head teacher cannot interfere with teachers' work. 